\title{
Quantification of the torrefaction effects on the grindability and the hygroscopicity of wood chips
}

Colin, B., Dirion, J-L. ${ }^{*}$, Arlabosse, P., Salvador, S.

Université de Toulouse, Mines Albi, CNRS UMR 5302, Centre RAPSODEE, Campus Jarlard, F-81013 ALBI Cedex 09, FRANCE.

${ }^{*}$ Corresponding author: dirion@mines-albi.fr

\section{Abstract}

In the field of biomass torrefaction, lots of product properties have been widely investigated at the lab scale but some uncertainties remain about the gains in terms of grindability and hygroscopicity of torrefied products. In this study, beech wood chips (with an initial moisture content of 10-12\%) have been torrefied in a pilot-scale rotary kiln. The torrefaction severity was controlled by adjusting the temperature, the treatment duration and the solid hold-up in the kiln. Mass losses ranging between $1.7 \%$ and $25 \%$ have been obtained. Properties of torrefied wood chips were then analyzed in terms of composition, heat content, hygroscopicity and grinding energy requirement. Dynamic vapor sorption measurements show that a minimum of hygroscopicity is reached for a mass loss (ML) between 1.7 and $7.8 \%$. The moisture uptakes for mass losses above this optimum remain stable at values twice lower than that of raw biomass. Finally, a new method is proposed to estimate the grindability of wood chips. This method takes into account the grinding energy consumption and the particle size distribution of ground samples. A reduction by a factor of 6.3 of the apparent specific surface grinding energy is observed between a moisture content of $41 \%$ and the dryness. This energy measurement is in turn reduced by a further factor of 8.1 after torrefaction with a $25 \%$ mass loss. 
Keywords: wood chips; torrefaction; grinding energy consumption; hygroscopicity.

\section{Introduction}

The development of renewable energy supply chains is a major issue in the actual context of global warming and fossil fuels depletion. Worldwide, bioenergy represents $80 \%$ of the total amount of renewable energy produced in 2012 [1]. Moreover, the use of biomass for power generation is expected to double in the EU by 2020, as part of the $20 / 20 / 20$ target. Considering bioenergy, the two main pathways are the use of solid biofuels (mainly valorized by combustion) and the production of gaseous biofuels (especially syngas obtained via gasification). These applications classically use wood chips as a source of energy. In the case of combustion, one way to produce heat and/or electricity at a large scale is to convert existing coal-fired power-plants into cofiring plants (simultaneous combustion of coal and biomass), with limited impact on efficiency and operations. The main existing method uses injection of milled biomass through pipes but the biomass-coal ratio remains very low because the combustion behavior of biomass is too far from the one of coal [2]. Concerning the second pathway, an efficient gasification, for example in an entrained-flow reactor, requires a high accessibility of wood to the gaseous reactants $\left(\mathrm{CO}_{2}\right.$, $\mathrm{H}_{2} \mathrm{O}$...). The external surface of particles is thus classically increased by means of grinding that represents a very costly step [3]. The main limitations to the use of large amounts of biomass at the industrial scale are thus its low energy density, its inappropriate composition compared to coal and the large energy requirement of the grinding step. These drawbacks could be overcome by performing torrefaction. 
Torrefaction of biomass is a thermal treatment at low temperature (250 $300^{\circ} \mathrm{C}$ ) under inert atmosphere [4]. Under heat effect, hemicelluloses of wood are decomposed. This leads to a biomass with a modified chemical composition presenting new properties. Torrefied biomass is for example considered as more brittle [5], less hygroscopic [6] and has a higher energy density than raw biomass [7]. Even if these aspects have been often studied at the laboratory scale, one of the major challenges is now the research of the optimal degree of torrefaction [8]. One of the main objectives is then to correlate the mass loss with the operating parameters on the one hand and with the product properties on the other hand. In the literature, the main operating parameters identified to control the torrefaction process are the temperature, the treatment duration [9] and the atmosphere composition as shown by Rousset et al. [10] and Wang et al. [11]. Effects of these parameters on the mass yield are now well known. In the same manner, the composition and the heat content of torrefied products have been widely investigated but some properties have not yet been clearly correlated with the mass loss. This is the case of the hygroscopicity about which some uncertainties remain: it is not clear if the hygroscopicity is correlated to the mass loss on the whole torrefaction domain or if the hygroscopicity remains stable above a given mass loss. Several authors have identified evaluation issues related to the grinding energy consumption. The most used indicator is the Hardgrove Grindability Index (HGl) initially developed for coal. Applied to biomass, this indicator could lead to unfavorable results as reported by Bergman et al. [12]. Indeed, only the most resistant part of the material is considered with this method, even if it represents a minor part of the overall 
matter in the case of wood. Other methods classically used to compare the grindability of various kinds of biomass are the energy consumption during a grinding experiment [13] or the comparison of the particle size distributions of ground samples [14]. Only one attempt has been made to take simultaneously into account the grinding energy consumption and the particle size. Repellin et al. [5] proposed to divide the grinding energy by the volumetric fraction of particles smaller than $200 \mu \mathrm{m}$. Even if this indicator is more reliable than the grinding energy alone, it looks insufficient to exhaustively compare ground samples with various particle size distributions. Finally, Temmerman et al. [15] proposed a comparison between the classical milling theories and recent published works on grinding energy requirement of biomass. They concluded that there is a lack of consensus in the literature on the calculation methods to determine the grinding energy of biomass. Since then, they evidenced that the Von Rittinger constant could be used to accurately establish the grindability of wood chips and pellets. However, this constant does not take into account the entire distribution of the ground product since it uses only the distribution median.

In this paper, the influence of operating parameters on torrefaction performed in a pilot rotary kiln is studied. The properties of torrefied biomass are evaluated in terms of ultimate, proximate and fiber analysis, hygroscopicity and grindability. A new method to characterize biomass grindability is proposed and applied to wet, dry and torrefied wood chips.

\section{Materials and methods}

\subsection{Materials}


Biomass used for this study is made of beech wood chips provided by a French Company (SPPS, Frasne, France). As received, the moisture content of wood chips was $10-12 \%$ on a dry basis (db). The dimensions of the chips are 5$15 \mathrm{~mm}$ in length, $2-7 \mathrm{~mm}$ in width and $1-3 \mathrm{~mm}$ in thickness. These dimensions have been measured for about 200 particles. Wood chips are bark-free, dustfree and calibrated to be easily handled. The bulk density of this feedstock is $280 \mathrm{~kg} / \mathrm{m}^{3}$.

\subsection{Torrefaction process}

The torrefaction of wood chips has been conducted in a pilot-scale rotary kiln

(Fig. 1) made of a rotating cylinder electrically heated. The cylinder is $4.2 \mathrm{~m}$ in length and $0.21 \mathrm{~m}$ in internal-diameter. The inner wall is covered by a metal grid to increase the adhesion to the particles and favor their progress along the kiln. This grid is made of $4 \mathrm{~mm}$ stainless steel rods and each grid cell is $250 \mathrm{~mm}$ long and $40 \mathrm{~mm}$ wide. The kiln slope can vary between 0 and $7^{\circ}$ and the rotational speed can be set between 1 and $21 \mathrm{rpm}$. The furnace is $2.5 \mathrm{~m}$ in length and its extremities are insulated to limit heat losses. It can be controlled from room temperature to $1000^{\circ} \mathrm{C}$. A thin layer of air separates the cylinder from the furnace. At the quite low torrefaction temperatures, the cylinder is thus mainly heated by convection and, to some extent, by radiation.

Wood chips are fed into the cylinder from the hopper with a vibrating conveyor whose amplitude is controlled by measuring continuously the overall mass of the feeding system. The inlet mass flowrate is thus accurately controlled $( \pm 2 \%)$. At the kiln-end, torrefied wood chips are collected in a metal container. 
This one is closed hermetically and swept with nitrogen to avoid the oxidation of the product during the cooling phase. Volatile matters produced by torrefaction are carried away from the reactor with nitrogen into a thermal oxidizer. The entire kiln is swept with nitrogen $\left(1 \mathrm{Nm}^{3} / \mathrm{h}\right)$ to maintain an overpressure.

In a previous study [16], the solid hold-up $H$ (ratio between the volume of wood chips in the kiln and the volume of the cylinder) and the mean residence time (MRT) of particles have been correlated with the operating parameters (inclination, rotational speed and feed rate). The operating parameters retained here are thus the solid hold-up, the mean residence time and the furnace temperature $T$. Parameters used during experimental runs are summarized in Table 1.

For each run, once the steady state is reached - after usually 4 hours - an empty container is placed at the outlet of the kiln. The torrefied wood is then sampled during $1 \mathrm{~h}$. The filled container is nitrogen-swept and weighed after cooling. The mass yield $\eta$ (in \%), defined on a dry basis, and the mass loss $M L$ (in \%) are computed according to Eq. (1) and Eq. (2), respectively.

$\eta=\frac{M_{t o r}}{\dot{M}_{h}} \times\left(1+\frac{M C}{100}\right) \times 100$

$M L=100-\eta \quad$ Eq. (2)

Where $M_{\text {tor }}$ is the mass of torrefied wood chips collected during 1 hour (in $\mathrm{kg}$ ), $\dot{M}_{h}$ is the inlet flow rate of raw wood chips (in $\mathrm{kg} / \mathrm{h}$ ) and $M C$ is the initial moisture content on a dry basis (in \%).

\subsection{Analysis of products composition and energy content}




\subsubsection{Higher heating value and energy yield}

The higher heating value (HHV) has been measured using an adiabatic bomb calorimeter IKA C5000 (IKA, Staufen, Germany). A pellet made with a previously ground sample (torrefied or not), whose mass is known, is burnt in the presence of an excess amount of oxygen. The elevation of temperature of the surrounding water allows the calculation of the $H H V$ (in $\mathrm{MJ} / \mathrm{kg}$ ). These measurements have been made in triplicates for each sample; the dispersion was typically $1 \%$. Knowing the higher heating values of torrefied ( $\left.H H V_{\text {torrefied }}\right)$ and raw $\left(H H V_{\text {raw }}\right)$ woods, the energy yield $\left(\eta_{\text {ener }}\right)$ of the torrefaction process can be calculated according to Eq. (3).

$\eta_{\text {ener }}=\eta \times H H V_{\text {torrefied }} / H H V_{\text {raw }} \quad$ Eq. (3)

\subsubsection{Ultimate and proximate analysis}

An elemental analyzer NC 2100 (CE Instruments, Wigan, England) has been used to determine the ultimate analysis of samples. Measurements were made in triplicates with known amounts of 2-4 mg of ground material. The analyzer returns $\mathrm{C}, \mathrm{H}, \mathrm{N}$ and $\mathrm{S}$ contents and the $\mathrm{O}$ content is deduced by difference.

Proximate analysis have been conducted in a muffle furnace according to the standard methods NF EN 15148:2010-03 for the volatile matters content (VM) and NF EN 14775:2010-03 for the ash content $(A C)$. The amount of ground sample, previously dried, used for each test was $1 \mathrm{~g}$. All these determinations have been made in triplicates too. The dispersion was typically $0.4 \%$ and $8 \%$ 
for the volatile matters content and the ash content respectively. The fixed carbon content $(F C)$ has been calculated by difference.

\subsubsection{Fiber analysis}

It has been chosen to use a modified Van Soest method to evaluate the fiber composition of biomass samples (torrefied or not). This method, initially developed for forages, has already been applied to forest biomass as in Reza et al. [17]. An A200 device (Ankom, Macedon, USA) has been used and approximately $0.5 \mathrm{~g}$ of oven-dried and ground wood chips was necessary for each analysis. The samples were first treated with a neutral detergent solution (sodium sulfite, triethylene glycol, sodium lauryl sulfate, dihydrate EDTA disodium, decahydrate sodium borate, dibasic anhydrous sodium phosphate and distilled water). During this phase, the wood extractives are removed. The residue (NDF in \%) contains all the cell wall polymers (hemicellulose, cellulose and lignin) except pectin which is highly soluble. The second phase consists of applying an acid attack on this residue (with sulfuric acid $1 \mathrm{~mol} / \mathrm{L}$ and cetyltrimethylammonium bromide) to mainly remove hemicelluloses. The residue is called $A D F$ (in \%). The last step is carried out with concentrated sulfuric acid (72\%). Even if some insoluble components like ashes, silica, heatdamaged proteins remain in the residue ( $A D L$ in \%), its main constituent is lignin. The fiber composition of solids can then be estimated using Eq. (4) to (7).

Extractives (\%) $\approx 100-N D F \quad$ Eq. (4)

Hemicellulose $(\%) \approx N D F-A D F \quad$ Eq. (5) 
Cellulose $(\%) \approx A D F-A D L$

$\operatorname{Lignin}(\%) \approx A D L$

Eq. (7)

\subsection{Evaluation of the hygroscopicity}

Sorption isotherms of raw biomass and of some torrefied products have been measured to evaluate the impact of torrefaction on the affinity of wood to water. These measurements have been performed using a dynamic vapor sorption apparatus DVS-2 (Surface Measurement System, London, England). Two measurement quartz pans (one for the sample, another for the reference) are suspended to a microbalance. These pans are placed in two chambers swept with a mixture of pure nitrogen and water vapor whose proportions are controlled to obtain a chosen relative humidity $(\mathrm{RH})$. The overall system is placed in an isothermal chamber that can be regulated between room temperature and $45^{\circ} \mathrm{C}$. Temperature and humidity probes are located under the pans and continuously record the characteristics of the gas. The relative humidity is planned to increase or decrease depending on whether the isotherm is studied in adsorption or in desorption mode.

As the objective is here to simulate the moisture uptake of wood chips after the torrefaction process, it has been chosen to determine the adsorption isotherm for relative humidities in the range 0 to $70 \%$ with a step of $10 \%$. An amount of approximately $0.7 \mathrm{~g}$ of oven-dried chips is placed on the pan and the apparatus is initially swept with pure nitrogen $(\mathrm{RH}=0 \%)$ until the mass remains stable. The $\mathrm{RH}$ is then increased and the transition from a relative humidity to the next one is realized when one of the two following criteria is fulfilled: the first criterion 
considers that equilibrium is reached when the mass variation is lower than $0.0007 \% / \mathrm{min}$; the second one is fulfilled when the time spent on the current step exceeds $500 \mathrm{~min}$.

\subsection{Evaluation of the grindability}

\subsubsection{Measurement of the grinding energy requirement}

An experimental procedure has been developed to measure the grinding energy consumption. The power consumption of a laboratory knife-mill Pulverisette 15 (Fritsch, Idar-Oberstein, Germany) is continuously measured with a numeric wattmeter ISW 8350 (leS Instruments et Systèmes, Grigny, France). The power is then recorded every $1 \mathrm{~s}$ with a computer. The knife-mill is composed of a four steel-blades rotor and a grinding chamber equipped with two counter-knives. The nominal power of the electric motor is $2.1 \mathrm{~kW}$. Two screens perforated with trapezoidal meshes of diameters 0.5 and $1 \mathrm{~mm}$ have been used.

For each test, the power of the mill is first recorded during $100 \mathrm{~s}$ without adding chips in order to measure the idle consumption that was around $600 \mathrm{~W}$. Six samples of approximately $50 \mathrm{~g}$ (accurately weighed) of wood chips are then ground successively. The pressure applied to the fed biomass column is adjusted continuously to maintain the power consumption as close as possible to $1200 \mathrm{~W}$. This value has been retained because it is twice higher than idle power. This procedure was performed in duplicate for each wood sample.

The mean idle power was then subtracted to obtain power curves. After integration, the energy consumption was divided by the dry mass of ground 
chips to express the specific grinding energy requirements in $\mathrm{kJ} / \mathrm{kg}$ of dry matter (DM).

\subsubsection{Particle size distribution}

The biomass ground during the previous step was then divided with a riffle splitter to obtain representative samples. Approximately $20 \mathrm{~cm}^{3}$ of powder are necessary to perform particle size distribution analysis. The laser analyzer was a Mastersizer 3000 (Malvern Instruments Ltd, Malvern, England) and the carrier used to disperse particles was air.

\section{Results and discussion}

\subsection{Effect of torrefaction parameters on the mass yield}

As expected, Table 1 shows that the mass loss increases when the residence time and/or the temperature increases. This is due to decomposition reactions that occur during torrefaction. The impact of temperature appears to be more significant that the one of residence time. Indeed, for a residence time of 66.7 min and a solid hold-up of $10.8 \%$, the mass loss rises from $1.7 \%$ to $25 \%$ when the temperature increases from 250 to $300^{\circ} \mathrm{C}$ (respectively runs 1 and 9). On the other hand, for runs at $280^{\circ} \mathrm{C}$ with a solid hold-up close to $11 \%$, the rise in mass loss is only $3.5 \%$ (from 12.9 to $16.4 \%$ ) when the residence time moves from 33.0 to $66.7 \mathrm{~min}$ (respectively runs 7 and 8 ).

It can be observed that the solid hold-up has an impact on the mass loss too: the higher the hold-up, the higher the mass loss. This unexpected observation has been previously correlated with higher temperatures measured inside the bed of particles when the solid hold-up is high [18]. In fact, exothermic reactions 
have been observed during the torrefaction process and these reactions could be favored by high bed depths that limit the evacuation of heat and volatiles matters produced.

3.2. Impact of torrefaction on the composition and the energy content of wood chips

As expected [19], it can be seen in Table 1 that the mass loss is accompanied by an increase of the higher heating value (HHV) that leads to energy yields higher than mass yields. The HHV rises from $19.46 \mathrm{MJ} / \mathrm{kg}$ for raw wood to $21.61 \mathrm{MJ} / \mathrm{kg}$ for wood chips torrefied with a mass loss of $25 \%$. The value of the energy yield is thus of $83.2 \%$. The higher energy density of torrefied wood chips in comparison with raw wood chips is especially important because this would lead to lower transportation costs and would contribute to limit the properties gap between wood and coal.

To understand the increase of HHV, the elemental composition can be observed (Table 2). The carbon content increases with the mass loss while the oxygen and the hydrogen contents decrease [20]. This is the result of the release of hydroxyl groups mainly located on hemicelluloses [21]. As the energy content is related to the carbon content, the rise from $47.19 \%$ (for raw biomass) to $54.00 \%$ (for torrefied biomass, run 9) of carbon can explain the HHV values measured. Finally, the nitrogen content remains very low, whatever the mass loss.

As volatile matters $(\mathrm{VM})$ are produced during torrefaction, their content in torrefied chips is lower than that in raw chips as shown by Pala et al. [22]. 
Moreover, it can be observed that VM decrease linearly with the mass loss. Consequently, ash contents and fixed carbon contents both increase proportionally when the mass loss increases, even if the ash content remains very low. Here again, torrefaction can be considered as a suitable pre-treatment to reduce the difference in burning behavior between biomass and coal, the latter having a high fixed carbon content (usually higher than $70 \%$ ).

Finally, the fiber composition brings significant insights about the evolution of the biomass wall polymer concentration during torrefaction. Actually, the easiest tendency to interpret is the one of hemicellulose. As represented in Fig. 2, it can be seen that hemicellulose content dramatically decreases even for low mass losses. For example, values of hemicellulose content are $22.81 \%$ and $17.90 \%$ for raw wood and torrefied wood with a mass loss of $1.7 \%$ respectively. As expected, hemicellulose is thus the most thermally sensitive component in biomass. However, hemicellulose decomposition is accompanied by an increase of extractives (see Table 2). Hemicelluloses broken during a light torrefaction remain in biomass as molecules slightly bound with fibers. For a more severe treatment, these compounds are evacuated with volatile matters and the extractives content decreases. For the torrefaction run at $300^{\circ} \mathrm{C}$, no more hemicellulose can be detected in torrefied biomass.

Looking at acid-soluble fibers (mainly composed by cellulose) in Table 2, it appears that for low mass losses (below $16.4 \%$ ), their content remains stable. When the mass loss reaches $25 \%$, the cellulose content decreases strongly. Finally, the acid-insoluble fraction (mostly lignin) increases slightly for mass losses ranging between 1.7 and $16.4 \%$ due to hemicellulose decomposition 
and a large increase is found when the mass loss rises to $25 \%$. These tendencies are probably the result of conjugated effects of cellulose degradation for the highest torrefaction temperatures and cellulose cross-linking that makes it insensitive to acid-attacks as proposed by Reza et al. [17].

\subsection{Evolution of the hygroscopicity with the torrefaction severity}

Results of dynamic vapor sorption experiments are presented Fig. 3. The measurements have been done at a temperature of $19.8 \pm 0.7^{\circ} \mathrm{C}$. The samples studied are raw chips and torrefied chips chosen to cover the overall range of mass losses. Even if values of moisture content are not available for the highest relative humidities, adsorption curves have sigmoidal shapes (IUPAC, type II). This behavior is characteristic of a multilayer adsorption of macroporous substrates as detailed by Sing [23]. This is consistent with previous studies on lignocellulosic materials [24].

It looks evident that the torrefied wood chips are less hygroscopic than raw beech chips. For example, at a relative humidity of $70 \%$, the raw biomass moisture content is $10.3 \%$ while it drops to $6.6 \%$ for chips torrefied with a mass loss of $1.7 \%$ and to $5.3 \%$ for other torrefied biomass $(\mathrm{ML}=7.4,16.4$ and $25.0 \%$ ). Another conclusion is that a minimum of hygroscopicity is reached for low mass loss (between 1.7 and $7.4 \%$ ). Above this point, the moisture content of torrefied chips is independent of the mass loss. This moisture content is thus twice smaller than the one of raw biomass. 
In the range of relative humidities studied here, the moisture content of chips torrefied with a mass loss of $1.7 \%$ is always higher than moisture contents of other torrefied chips. This gap increases with the relative humidity.

As a conclusion, the improvement of the adsorption behavior of biomass during torrefaction does not need to entirely remove hemicelluloses. In fact, the departure of hydroxyl groups, even at low mass losses, is sufficient to decrease significantly the hygroscopicity of the material. The gain could be substantial on the transport step and on the final valorization process yield.

3.4. The effects of moisture content and of torrefaction mass loss on the grindability of wood chips

\subsubsection{Analyzed samples}

The analyzed samples are wet wood, raw oven-dried wood and torrefied (ovendried) wood. Several samples have been artificially conditioned in order to observe the influence of the moisture content on the grindability of wood chips. A known amount of water has been pulverized on wood chips in closed containers. These containers have been stored during approximately 4 weeks to obtain the chosen equilibrium. During this period, wood chips have been mixed regularly to improve the homogeneity of moisture adsorption. The final moisture content $(\mathrm{MC})$ was then measured before each grinding experiment.

All the biomass samples have been ground using a screen perforated with trapezoidal meshes of diameters $0.5 \mathrm{~mm}$. Only one torrefied sample has been ground with a screen perforated with meshes of $1 \mathrm{~mm}$ for comparison. 


\subsubsection{Grinding energy requirement results}

Results are synthesized in Fig. 4 representing the specific grinding energy as a function of moisture content on the left side of the figure and torrefaction mass loss on the right side of the figure. It appears that drying wood chips enables to decrease significantly the grinding energy requirement. Indeed, this energy is divided by 4 when the moisture content decreases from $41 \%$ to $0 \%$.

The torrefaction step also decreases the specific grinding energy. The decrease is especially important for the low mass losses. It falls down from $218 \mathrm{~kJ} / \mathrm{kg}_{\mathrm{DM}}$ for raw biomass to $135 \mathrm{~kJ} / \mathrm{kg}_{\mathrm{DM}}$ for biomass with a mass loss of $1.7 \%$. The gain is then less significant but remains substantial: there is a factor 4 between the specific grinding energy of raw biomass and those of the torrefied biomass with a mass loss of $25 \%$. Finally, when the biomass is ground with the $1 \mathrm{~mm}$ screen, the energy consumption is twice lower than with the $0.5 \mathrm{~mm}$ screen. This clearly shows the influence of the particle size on the results of such a measurement. This feature will be treated in the next section.

\subsubsection{Taking into account the particle size distribution}

The particle size distributions of raw and torrefied biomass are presented in Fig. 5. The curve obtained for dry chips $(\mathrm{MC}=0 \%)$ shows a shift from large to small particles in comparison with wet particles (MC=12\%). This tendency is then more pronounced when the mass loss of biomass during torrefaction increases. One can observe that the smaller the particles are, the wider the distribution curve is. This reflects that a weaker structure will lead to more fine particles during the grinding step. The main results are summarized in Table 3. 
$d 10, d 50$ and $d 90$ are the particles diameters obtained from the cumulative distributions data at 10,50 and $90 \%$ respectively. The spreads of the distributions are called SPAN and are calculated according to Eq. (8).

$S P A N=(d 90-d 10) / d 50 \quad$ Eq. $(8)$

To provide a reliable indicator of the grindability, the grinding energy consumption has been expressed per unit of created surface. This method is particularly relevant in the field of biomass valorization because the objective of milling is to favor the accessibility of material to the process gases $\left(\mathrm{O}_{2}, \mathrm{CO}_{2}\right.$, $\mathrm{H}_{2} \mathrm{O}$ ) by increasing the external surface of the particles.

It was thus necessary to estimate the surfaces of wood chips and ground particles. As the laser analyzer assimilates all particles to spheres, this assumption has been conserved to calculate the surface of ground particles $S_{g p}$ (in $\mathrm{m}^{2} / \mathrm{kg}_{\mathrm{DM}}$ ) according to Eq. (9).

$S_{g p}=\sum_{i}\left(x_{i} S_{i} / V_{i}\right) / \rho \quad$ Eq. (9)

Where $x_{i}$ is the volumetric fraction of particles having a diameter $d_{i} . S_{i}$ and $V_{i}$ are respectively the surface area and the volume of these particles calculated with Eq. (10) and (11).

$$
\begin{array}{ll}
S_{i}=4 \pi\left(d_{i} / 2\right)^{2} & \text { Eq. (10) } \\
V_{i}=4 / 3 \pi\left(d_{i} / 2\right)^{3} & \text { Eq. (11) }
\end{array}
$$

The method used to determine the density $\rho$ of particles was here by measuring the length, width and thickness of parallelepiped chips and by weighing them. 
Values obtained for raw and torrefied biomass (ML=25\%) were $685 \pm 38 \mathrm{~kg} / \mathrm{m}^{3}$ and $669 \pm 58 \mathrm{~kg} / \mathrm{m}^{3}$ respectively. The relatively large uncertainty is due to the small size of particles. No significant difference has been highlighted between densities of raw and torrefied particles. This is probably the result of conjugated effects of mass loss and volumetric shrinkage during torrefaction.

The diameter retained to calculate the surface of wood chips, according to the previous equations, is the mean value of the three dimensions (length, width, thickness). The difference between the surface of wood chips and the surface of ground particles is thus the surface created during the grinding step (see Table 3).

Knowing this surface, results of grinding energy can be expressed in $\mathrm{kJ} / \mathrm{m}^{2}$ created. Here, this indicator is called apparent specific surface grinding energy and values are presented Fig. 6 .

For moisture contents higher than $20 \%$ the apparent specific surface grinding energy remains almost constant. This can be explained by the evolution of the surface created which depends on the moisture content. Indeed, the higher the moisture content, the higher the surface created. Two explanations have been given to understand this phenomenon. Firstly, when the moisture content is high, large amounts of fine particles have been observed after grinding, probably due to a partial obstruction of the screen increasing the time spent in the grinding chamber. The second reason is that particles with high moisture contents undergo significant shrinkage during the drying step prior the size 
analysis. However, the apparent specific surface grinding energy of wood chips with a moisture content of $41 \%$ is 6.3 times higher than that of dry chips.

For torrefied wood chips, the tendency previously observed - without taking into account the particle size - is still noticeable. The main change concerns the order of magnitude of the apparent specific surface grinding energy decrease when increasing the mass loss. This energy falls down from $2.86 \mathrm{~kJ} / \mathrm{m}^{2}$ created for dry chips to $0.35 \mathrm{~kJ} / \mathrm{m}^{2}$ created for torrefied chips with a mass loss of $25 \%$. Torrefaction can thus decrease the energy requirement of grinding by a factor of 8.1 for a mass loss of $25 \%$.

The Fig. 2 allows the comparison between the hemicellulose content and the apparent specific surface grinding energy. As expected, for low mass losses, the apparent specific surface grinding energy decreases drastically, like the hemicellulose content. The decrease is then slightly lower and seems to approach an asymptote for the higher mass losses. The strength of the material is thus conferred by the remaining cellulose and the lignin, not decomposed by the torrefaction process.

Finally, the values of the apparent specific surface grinding energy obtained with screens of 0.5 and $1 \mathrm{~mm}$ are respectively 0.97 and $0.82 \mathrm{~kJ} / \mathrm{m}^{2}$ created. The gap between these values is not significant, which shows that the developed indicator is reliable for the determination of an intrinsic grindability of biomass, independently of the particle size.

\section{Conclusions}


During biomass torrefaction, changes in ultimate and proximate compositions lead to a material with a higher carbon content. Its energy content is thus increased. As the hydroxyl groups of hemicelluloses are removed, the water vapor sorption behavior is modified and a minimum of hygroscopicity is obtained for low mass losses, between 1.7 and $7.8 \%$. A method has been proposed for the evaluation of an intrinsic grindability of biomass, in taking simultaneously into account the milling energy consumption and the particle size of ground products. This method showed that the apparent specific surface

grinding energy is divided by 6.3 between chips with a moisture content of $41 \%$ and dry chips. This energy measure in turn is reduced by a further factor of 8.1 after torrefaction with a mass loss of $25 \%$.

\section{Acknowledgments}

The authors would like to acknowledge Philippe Accart, Denis Marty, Séverine Patry, Mickaël Ribeiro and Jean-Marie Sabathier for their technical support. 


\section{References}

[1] Guo M, Song W, Buhain J, 2015. Bioenergy and biofuels: History, status, and perspective. Renewable and Sustainable Energy Reviews, 42, 712-725.

[2] Goldfarb JL, Liu C, 2013. Impact of blend ratio on the co-firing of a commercial torrefied biomass and coal via analysis of oxidation kinetics. Bioresource Technology, 149, 208-215.

[3] Arias B, Pevida C, Fermoso J, Plaza M, Rubiera F, Pis J, 2008. Influence of torrefaction on the grindability and reactivity of woody biomass. Fuel Processing Technology, 89(2), 169-175.

[4] Bates RB, Ghoniem AF, 2012. Biomass torrefaction: Modeling of volatile and solid product evolution kinetics. Bioresource Technology, 124, 460-469.

[5] Repellin V, Govin A, Rolland M, Guyonnet R, 2010. Energy requirement for fine grinding of torrefied wood. Biomass and Bioenergy, 34(7), 923-930.

[6] Medic D, Darr M, Shah A, Rahn S, 2012. Effect of torrefaction on water vapor adsorption properties and resistance to microbial degradation of corn stover. Energy \& Fuels, 26(4), 2386-2393.

[7] Du SW, Chen WH, Lucas JA, 2014. Pretreatment of biomass by torrefaction and carbonization for coal blend used in pulverized coal injection. Bioresource Technology, 161, 333-339.

[8] Batidzirai B, Mignot APR, Schakel WB, Junginger HM, Faaij APC, 2013. Biomass torrefaction technology: Techno-economic status and future prospects. Energy, 62, 196-214.

[9] Medic D, Darr M, Shah A, Potter B, Zimmerman J, 2012. Effects of torrefaction process parameters on biomass feedstock upgrading. Fuel, 91(1), 147-154.

[10] Rousset P, Macedo L, Commandré JM, Moreira A, 2012. Biomass torrefaction under different oxygen concentrations and its effect on the composition of the solid by-product. Journal of Analytical and Applied Pyrolysis, 96, 86-91.

[11] Wang C, Peng J, Li H, Bi XT, Legros R, Lim CJ, Sokhansanj S, 2013. Oxidative torrefaction of biomass residues and densification of torrefied sawdust to pellets. Bioresource Technology, 127, 318-25.

[12] Bergman PCA, Boersma AR, Kiel JHA, Prins MJ, Ptasinski KJ, Janssen FJJG, 2004. Torrefaction for entrained-flow gasification of biomass. ECN Biomass, 1-50. 
[13] Kokko L, Tolvanen H, Hämäläinen K, Raiko R, 2012. Comparing the energy required for fine grinding torrefied and fast heat treated pine. Biomass and Bioenergy, 42, 219-223.

[14] Eseltine D, Thanapal SS, Annamalai K, Ranjan D, 2013. Torrefaction of woody biomass (Juniper and Mesquite) using inert and non-inert gases. Fuel, 113, 379-388.

[15] Temmerman M, Jensen PD, Hébert J, 2013. Von Rittinger theory adapted to wood chip and pellet milling, in a laboratory scale hammermill. Biomass and Bioenergy, 56, 70-81.

[16] Colin B, Dirion JL, Arlabosse P, Salvador S, 2015. Wood chips flow in a rotary kiln: experiments and modeling. Chemical Engineering Research and Design, In Press.

[17] Reza MT, Uddin MH, Lynam JG, Coronella CJ, 2014. Engineered pellets from dry torrefied and HTC biochar blends. Biomass and Bioenergy, 63, 229238.

[18] Colin B, Dirion JL, Arlabosse P, Salvador S, 2014. Experimental study of wood chips torrefaction in a pilot-scale rotary kiln. Chemical Engineering Transactions, 37, 505-510.

[19] Pimchuai A, Dutta A, Basu P, 2010. Torrefaction of agriculture residue to enhance combustible properties. Energy \& Fuels, 24(9), 4638-4645.

[20] Pilon G, Lavoie J, 2011. Characterization of switchgrass char produced in torrefaction and pyrolysis conditions. BioResources, 6(4), 4824-4839.

[21] Weiland JJ, Guyonnet R, 2003. Study of chemical modifications and fungi degradation of thermally modified wood using DRIFT spectroscopy. Holz Als Roh- Und Werkstoff, 61, 216-220.

[22] Pala M, Kantarli IC, Buyukisik HB, Yanik J, 2014. Hydrothermal carbonization and torrefaction of grape pomace: A comparative evaluation. Bioresource Technology, 161, 255-262.

[23] Sing KSW, 1982. Reporting physisorption data for gas/solid systems with special reference to the determination of surface area and porosity. Pure and Applied Chemistry, 54(11), 2201-2218.

[24] Hill CAS, Norton AJ, Newman G, 2010. The water vapour sorption properties of Sitka spruce determined using a dynamic vapour sorption apparatus. Wood Science and Technology, 44(3), 497-514. 


\section{Tables}

\section{Table 1}

Operating parameters ( $T, H$ and $M R T)$, mass loss, mass and energy yields, and higher heating value $H H V$ for the torrefaction experiments in the rotary kiln.

Values in brackets are the measurement uncertainties on HHV values.

\begin{tabular}{|c|c|c|c|c|c|c|c|}
\hline Run & $\begin{array}{c}\mathrm{T} \\
\left({ }^{\circ} \mathrm{C}\right)\end{array}$ & $\begin{array}{l}H \\
(\%)\end{array}$ & $\begin{array}{l}\text { MRT } \\
(\mathrm{min})\end{array}$ & $\begin{array}{l}\text { Mass loss } \\
(\%)\end{array}$ & $\begin{array}{l}\text { Mass yield } \\
(\%)\end{array}$ & $\begin{array}{c}\mathrm{HHV} \\
(\mathrm{MJ} / \mathrm{kg})\end{array}$ & $\begin{array}{c}\text { Energy } \\
\text { yield } \\
(\%) \\
\end{array}$ \\
\hline Raw & - & - & - & 0 & 100 & $\begin{array}{l}19.46 \\
(0.23)\end{array}$ & 100 \\
\hline 1 & 250 & 10.8 & 66.7 & 1.7 & 98.3 & $\begin{array}{l}19.82 \\
(0.09)\end{array}$ & 100 \\
\hline 2 & 280 & 4.9 & 21.8 & 7.4 & 92.6 & $\begin{array}{l}19.88 \\
(0.04)\end{array}$ & 94.6 \\
\hline 3 & 270 & 13.0 & 54.4 & 10.2 & 89.8 & $\begin{array}{l}20.02 \\
(0.14)\end{array}$ & 92.4 \\
\hline 4 & 280 & 5.2 & 32.7 & 10.6 & 89.4 & $\begin{array}{l}20.34 \\
(0.10)\end{array}$ & 93.5 \\
\hline 5 & 270 & 18.1 & 55.9 & 11.3 & 88.7 & $\begin{array}{l}19.98 \\
(0.09)\end{array}$ & 91.0 \\
\hline 6 & 270 & 10.8 & 66.7 & 11.8 & 88.2 & $\begin{array}{l}20.02 \\
(0.12)\end{array}$ & 90.7 \\
\hline 7 & 280 & 10.6 & 33.0 & 12.9 & 87.1 & $\begin{array}{l}20.04 \\
(0.10)\end{array}$ & 89.7 \\
\hline 8 & 280 & 10.8 & 66.7 & 16.4 & 83.6 & $\begin{array}{l}20.42 \\
(0.20)\end{array}$ & 87.7 \\
\hline 9 & 300 & 10.8 & 66.7 & 25.0 & 75.0 & $\begin{array}{l}21.61 \\
(0.09)\end{array}$ & 83.2 \\
\hline
\end{tabular}




\section{Table 2}

Elemental, proximate and fiber compositions of raw and torrefied biomass.

Values in brackets are uncertainties calculated with at the $95 \%$ confidence

level.

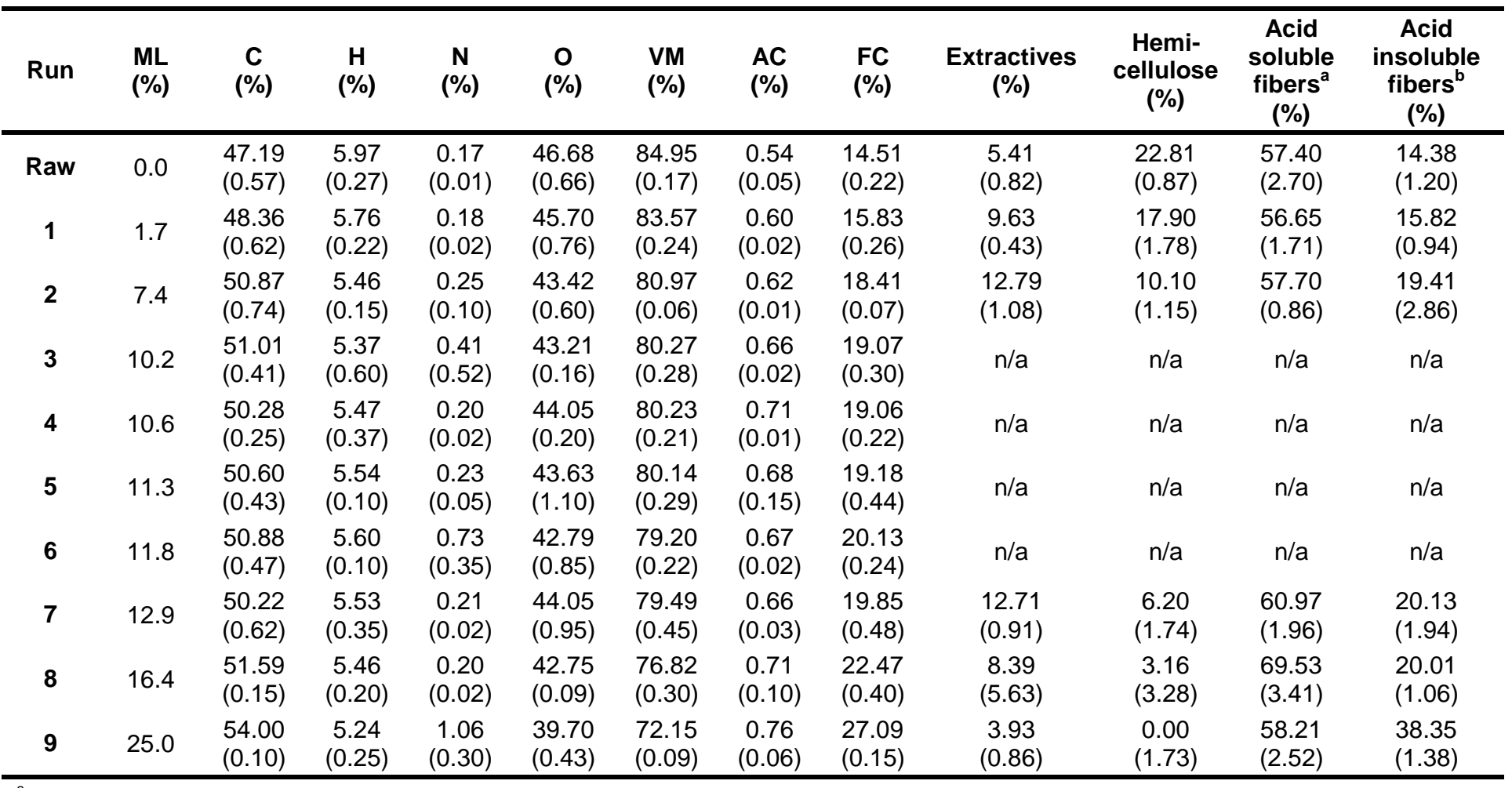

${ }^{a}$ Mostly cellulose

${ }^{b}$ Mostly lignin 


\section{Table 3}

Characteristics of the distribution curves and created surface calculated for each sample.

\begin{tabular}{cccccccc}
\hline Biomass & $\begin{array}{c}\mathbf{M C} \\
(\%)\end{array}$ & $\begin{array}{c}\mathbf{M L} \\
(\%)\end{array}$ & $\begin{array}{c}\mathbf{d} \mathbf{( 1 0} \\
(\boldsymbol{\mu m})\end{array}$ & $\begin{array}{c}\mathbf{d 5 0} \\
(\boldsymbol{\mu m})\end{array}$ & $\begin{array}{c}\mathbf{d 9 0} \\
(\boldsymbol{\mu m})\end{array}$ & $\begin{array}{c}\text { SPAN } \\
(-)\end{array}$ & $\begin{array}{c}\text { Created surface } \\
\left(\mathbf{m}^{2} / \mathbf{k g}\right)\end{array}$ \\
\hline Raw & 41.4 & 0 & 69 & 306 & 756 & 2.24 & 50.7 \\
Raw & 31.8 & 0 & 75 & 327 & 837 & 2.33 & 47.4 \\
Raw & 20.5 & 0 & 120 & 382 & 862 & 1.94 & 33.5 \\
Raw & 11.6 & 0 & 132 & 380 & 830 & 1.84 & 32.3 \\
Raw & 0 & 0 & 64 & 293 & 696 & 2.16 & 76.0 \\
Torrefied & 0 & 1.7 & 50 & 244 & 591 & 2.22 & 81.8 \\
Torrefied & 0 & 7.4 & 42 & 220 & 563 & 2.36 & 98.7 \\
Torrefied & 0 & 10.2 & 37 & 202 & 538 & 2.48 & 110.5 \\
Torrefied & 0 & 10.6 & 39 & 210 & 533 & 2.36 & 105.4 \\
Torrefied & 0 & 11.3 & 36 & 197 & 506 & 2.39 & 113.2 \\
Torrefied & 0 & 11.8 & 36 & 194 & 470 & 2.24 & 111.5 \\
Torrefied & 0 & 12.9 & 36 & 194 & 494 & 2.36 & 111.7 \\
Torrefied & 0 & 12.9 & 77 & 389 & 1282 & 3.10 & 51.1 \\
Torrefied & 0 & 16.4 & 35 & 196 & 485 & 2.29 & 115.8 \\
Torrefied & 0 & 25.0 & 25 & 161 & 442 & 2.60 & 142.7 \\
\hline
\end{tabular}

*Ground with a $1 \mathrm{~mm}$ grid 


\section{Figure Captions}

Fig. 1: Schematic representation of the pilot-scale rotary kiln. 1: feeding hopper,

2: vibrating conveyor, 3: weighing system, 4: rotating cylinder, 5: furnace, 6 : heated outlet, 7: gate valve, 8: metal container.

Fig. 2: Hemicellulose content and apparent specific surface grinding energy versus torrefaction mass loss.

Fig. 3: Adsorption isotherms of raw wood chips and torrefied wood chips with various mass losses.

Fig. 4: Specific grinding energy for raw (wet and dry) and torrefied chips.

Fig. 5: a) Particle size distribution and b) cumulative passing curves for raw and torrefied ground samples.

Fig. 6: Apparent specific surface grinding energy for raw (wet and dry) and torrefied chips. 
Fig. 1

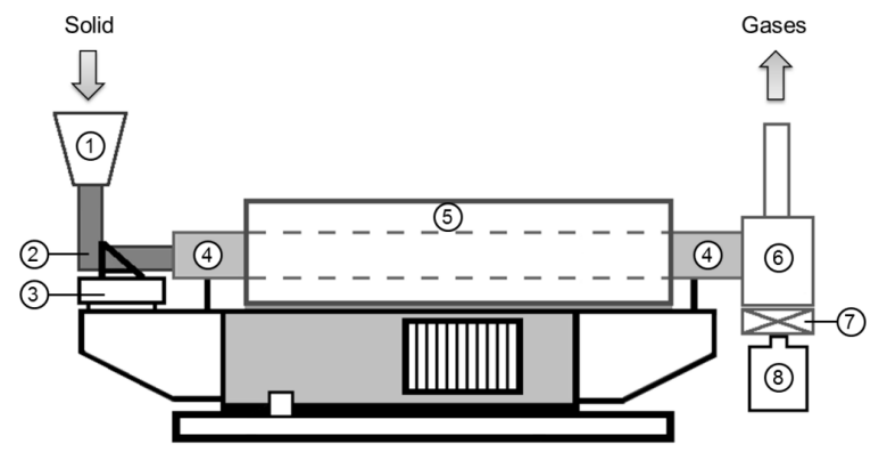


Fig. 2

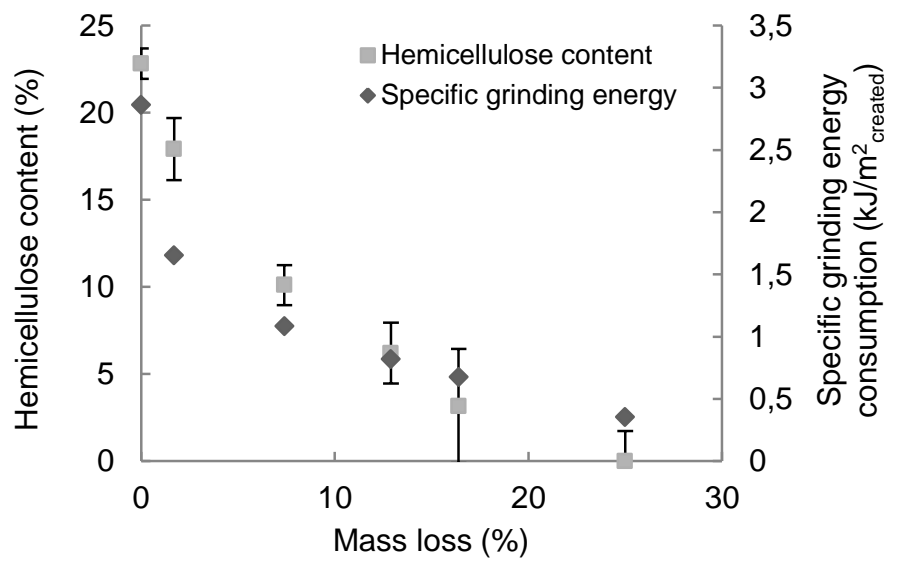


Fig. 3

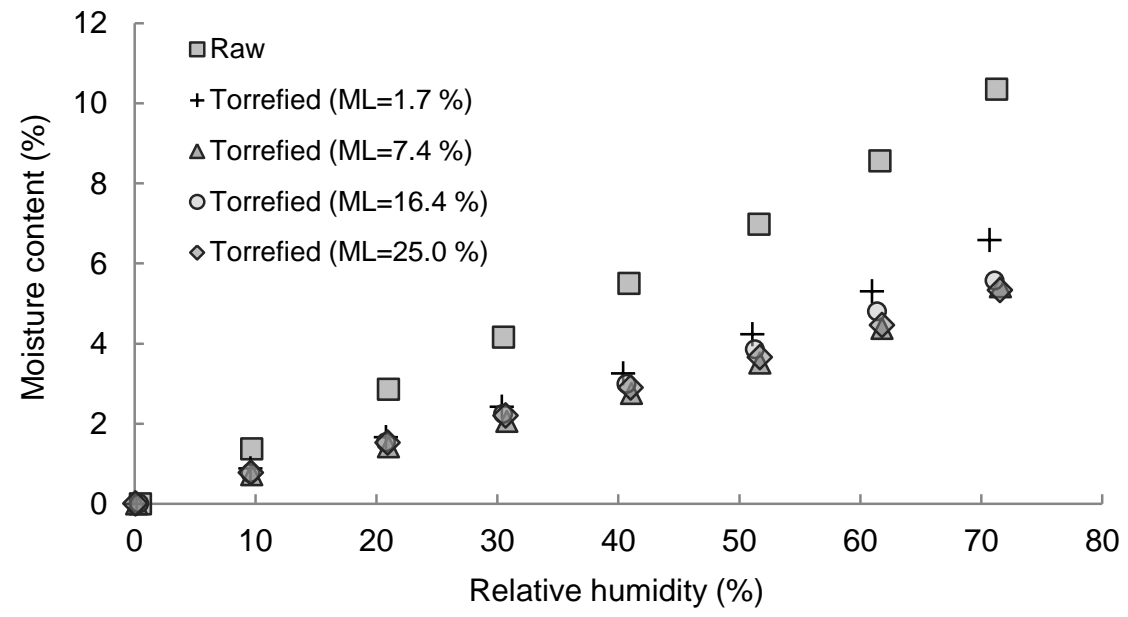


Fig. 4

\section{Grinding energy consumption ( $\left.\mathrm{kJ} / \mathrm{kg}_{\mathrm{DM}}\right)$}

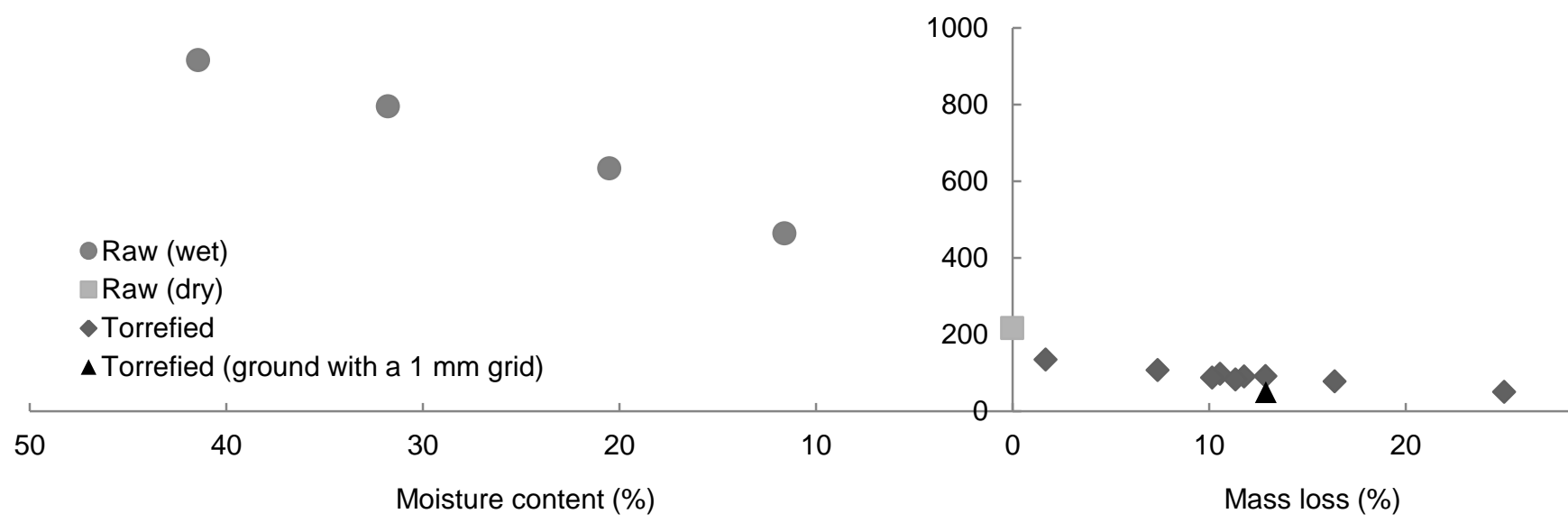


Fig. 5
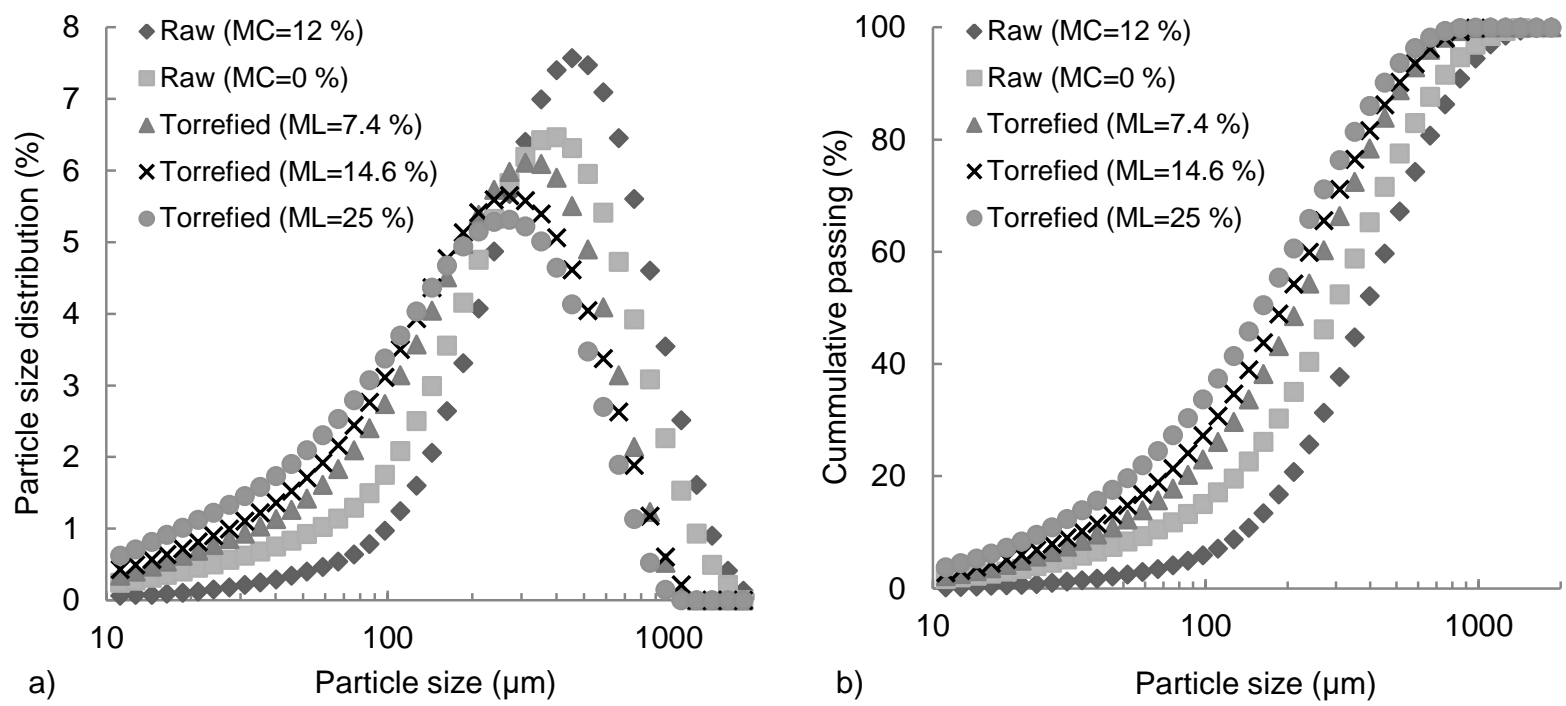
Fig. 6

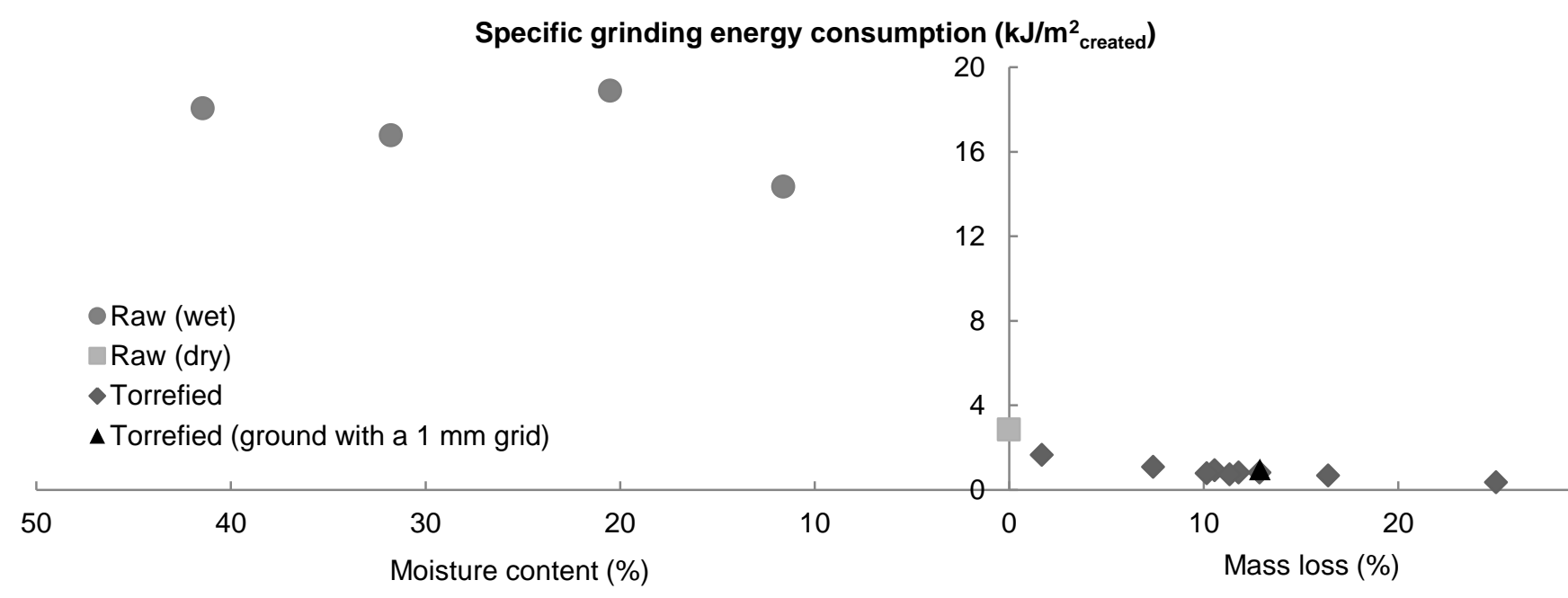

